Çukurova Üniversitesi Mühendislik Mimarlık Fakültesi Dergisi, 34(3), ss. 85-94, Eylül 2019

Çukurova University Journal of the Faculty of Engineering and Architecture, 34(3), pp. 85-94, September 2019

\title{
Açık Ocak Üretim Planlaması için Örnek Bir Uygulama
}

\author{
Ebru KARAKURT ${ }^{* 1}$, Ahmet Hakan ONUR ${ }^{2}$ \\ ${ }^{1}$ Dokuz Eylül Üniversitesi, Fen Bilimleri Enstitüsü, Maden İşletmesi Anabilim Dall, İzmir \\ ${ }^{2}$ Dokuz Eylül Üniversitesi, Mühendislik Fakültesi, Maden Mühendisliği Bölümü, İzmir
}

\section{$\ddot{O} z$}

Geliş tarihi: 03.07.2019 Kabul tarihi: 30.09 .2019

Madenler, milyonlarca yılda oluşan, tüketildiğinde yenilenemeyen kaynaklardır. Bu nedenle; ülkenin ihtiyaçları göz önüne alınarak, kaynak kaybına yol açmadan, çevreyle barışık, akılcı, ekonomik kurallara göre ve işçi sağlığı-iş güvenliği esasları çerçevesinde, kamu yararı öncelikli olacak şekilde etkin bir planlama ile üretilmelidir [1]. Etkin bir planlama ise; değişen maliyet ve ürün değerine en hızlı şekilde uyum sağlayarak, rezervden elde edilebilecek net bugünkü değeri en yüksek üretimi sağlamalıdır.

Bu çalışmada bir açık ocağın ocak ömrü boyunca maksimum kâr ile üretim yapmasını sağlayacak ilerleme yönleri bilgisayar programı (MICROMINE 11.0 ve SURPAC 6.5.1) yardımıyla araştırılmıştır. Sahada yapılan sondajlardan elde edilen verilerle veri tabanı oluşturulmuştur. Jeoistatistiksel analizler (istatistik ve variogram analizleri) ile tenör-tonaj hesaplamaları yapılmış ve kriging yöntemi ile cevherin yataktaki dağılımı tespit edilmiştir. Kazı ve zenginleştirme aşamaları için öngörülen maliyetler belirlenmiştir. Cevher fiyatı değiştirilerek iç içe ocaklar serisi oluşturulmuş, oluşan ocak sınırlarındaki değişimler incelenerek cevher üretim sırası belirlenmiştir.

Anahtar Kelimeler: Açık ocak, Üretim planlama, İlerleme yönü, İç içe ocaklar, Karlılık

\section{A Sample Application for Open Pit Mine Production Planning}

\begin{abstract}
Minerals are nonrenewable resources formed over millions of years. Therefore; minerals must be produced with planning efficiently prioritizing the public interest within the frame of principles of occupational health and safety in accordance with environment friendly, rational and economical rules without loss of resource by taking needs of the country into consideration [1]. An effective planning must comply with changing cost and product value in the fastest way possible and yield the highest production with highest current value possible obtained from reserve.

In this study, heading directions which make an open pit mine to make production with maximum profit throughout its mine life are examined by means of computer program. A database is set by data acquired from borings made in the field. Grade-tonnage calculations are made by geostatistical analyses (statistical and variogram analyses) and distribution of ore within the mineral deposit is determined by kriging method. Costs estimated for mining and enrichment phases are determined. Nested pit is formed by changing ore price and ore production sequence is determined by examining changes within pit boundaries.
\end{abstract}

Key Words: Open pit mine, Production planning, Heading direction, Nested pit, Profitability

*Sorumlu yazar (Corresponding author): Ebru KARAKURT, e.karakurt@hotmail.com.tr 


\section{GíRiș}

Üretim planlamasında temel amaç rezervin maksimum kâr ile elde edilmesini sağlamaktır. Maksimum kârın belirlenmesinde ise nihai açık ocak sınırı ve üretim sıralaması olmak üzere iki temel etken bulunmaktadır [2]. Whittle [3] bu etkenleri belirlemedeki zorluğu "Maksimum ocak değerini veren nihai sınırlar, blokların ekonomik değerleri bilinmeden bulunamaz. Blok ekonomik değerleri ise blok kazı sırasına karar verilmeden bilinemez. Blok kazı sırası ise ocak nihai sınırları belirlenmeden bulunamaz [3]." sözü ile net bir şekilde ifade etmektedir [4]. Bir diğer yandan aynı nihai ocak sınırları içerisinde, uygulanması mümkün olan birçok farklı üretim sıralaması yapmak mümkündür [5]. Planlamanın önemi de tam olarak bu noktada ortaya çıkmaktadır. Dağdelen ve Johnson [6]'da üretim planlamasında en büyük problemin maksimum net bugünkü değeri sağlayacak olan kazı sıralamasının bulunması olduğunu ifade etmektedir [6]. Bu karmaşık problemin çözümü için Dinamik Programlama [7-9], Parametreleştirme [10], Kümeleme [11], Genetik Algoritma gibi pek çok yöntem geliştirilmiştir. Bu yöntemlerin birbirine göre üstün ve eksik yanlarını ortaya koyan çok sayıda araștırma bulunmaktadır. Yöntemlerin dezavantajlı yanları ve özellikle de sonuca ulaşma süresinin önemi planlamanın gelişime açık bir çalışma alanı olduğunu da ortaya koymaktadır.
$\mathrm{Bu}$ çalışmada Lerchs Grossman Algoritması kullanılarak Parametreleştirme Yöntemiyle gelir faktörüne bağlı iç içe ocaklar serisi (nested pits, pit sheells) oluşturulmuştur. Ürün fiyatı değiştirilip maliyetleri sabit tutularak ocak sinırlarındaki ilerleme hareketi incelenmiştir. Ocak nihai sınırına ulaşılana kadar ürün fiyatı yükseldikçe üretime değer bloklar ocak sınırının değişmesine neden olmaktadır. Bu değişim miktarı sabit tutularak sabit bir üretim kapasitesinde üretim dönemlerinin sonunda oluşacak ocak sınırları belirlenebilmektedir.

\section{2. ÇALIŞMA ALANI}

Çalışma sahasında, jeolojik ve jeokimyasal çalışmalar sonucunda belirlenmiş, KD-GB uzanımlı, yaklaşık $800 \mathrm{~m}$ uzunluğunda, yer yer 150 $\mathrm{m}$ genişliğinde, $\mathrm{Cu}$ cevherli-breşik bir zon bulunmaktadır. Cevherleşme zonlanması belirlenirken değerlendirmeye katılacak minimum

$\mathrm{Cu}$ tenörü $\% 0,3$ olarak dikkate alınmıştır. Ancak $\% 0,3$ tenör değerlerinin arasında daha düşük tenörlü seviyeler de bulunmaktadır. Bu nedenle sondajlarda kesilen cevherli seviyelerden $\% 0,3 \mathrm{Cu}$ tenörü ve üzerinde olan cevherli seviyelerin arasında kalan daha düşük tenörlü seviyelerden, 10 m'ye kadar olan kalınlıklar cevhere dahil edilmiş, 10 m'den daha kalın olan seviyeler steril kabul edilmiştir [12]. Şekil 1 ve Şekil 2'de yapılan sondajlara ait üst ve yan görünüm verilmektedir.

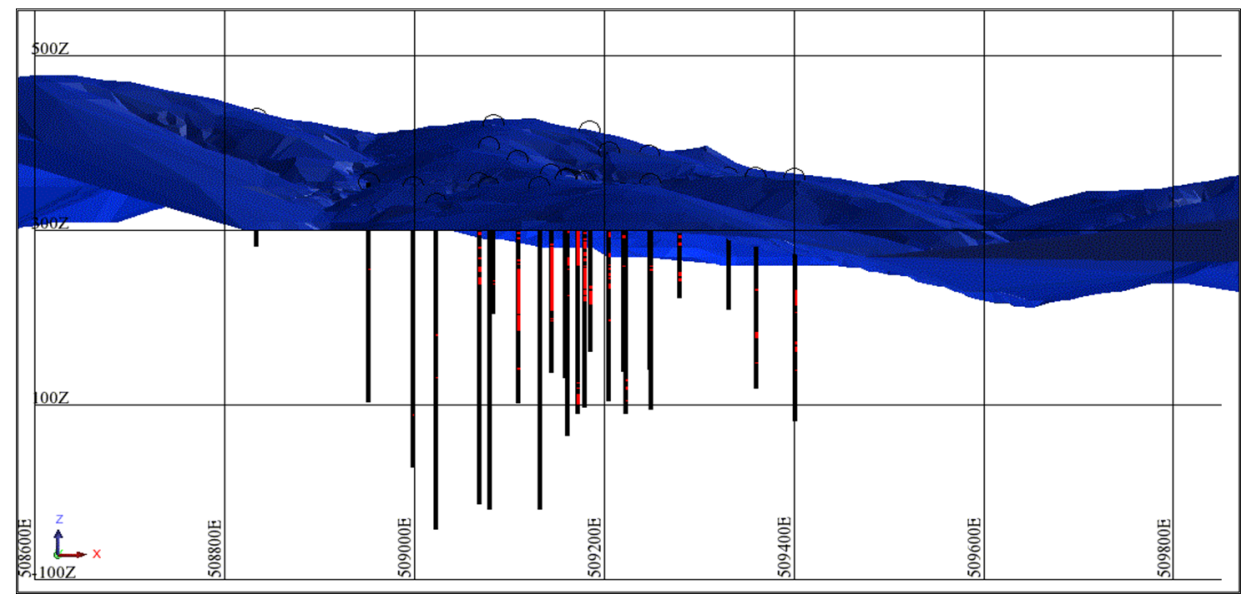

Şekil 1. Sondaj lokasyon haritası yan görünüm 


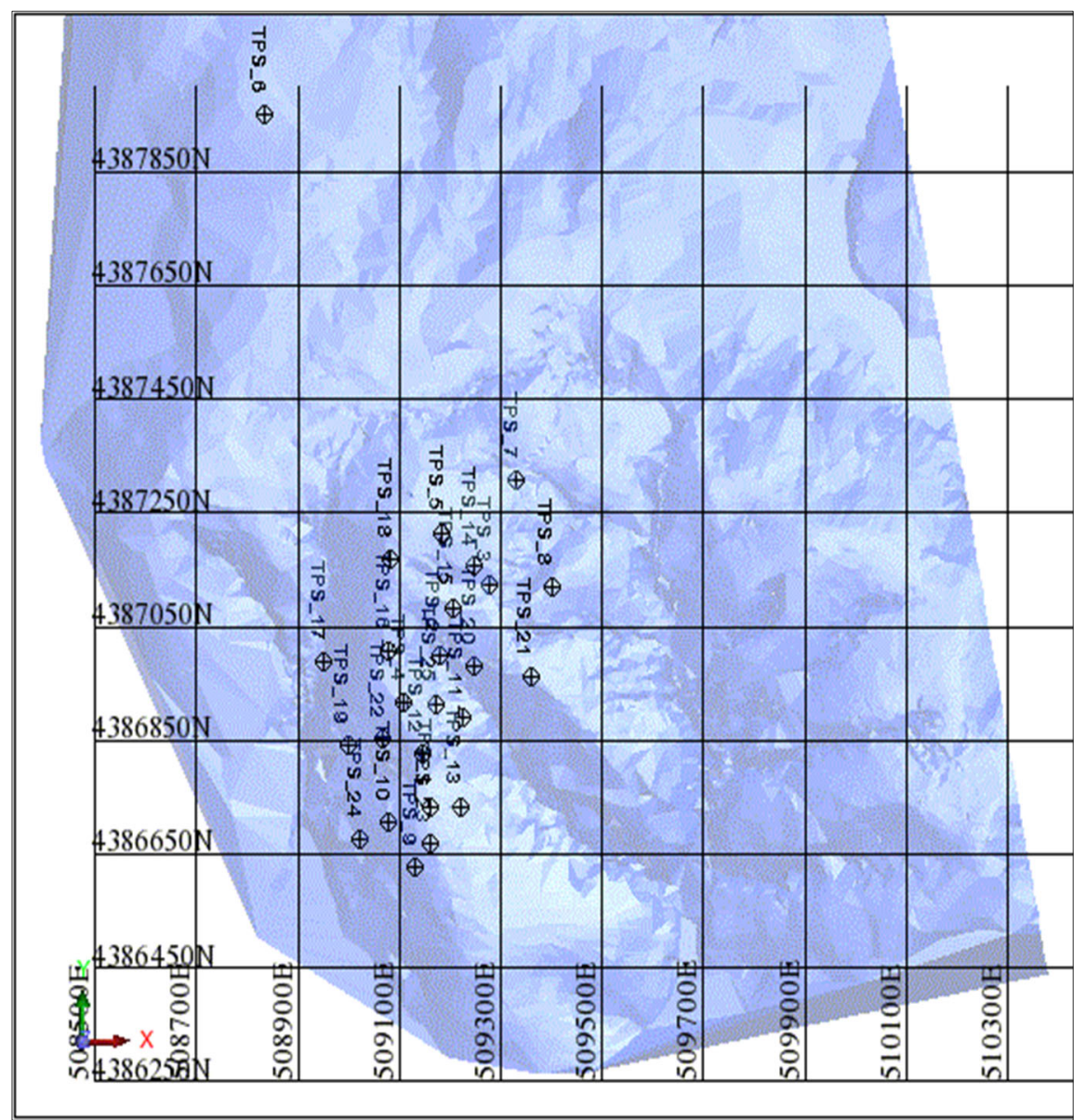

Şekil 2. Sondaj lokasyon haritası üst görünüm

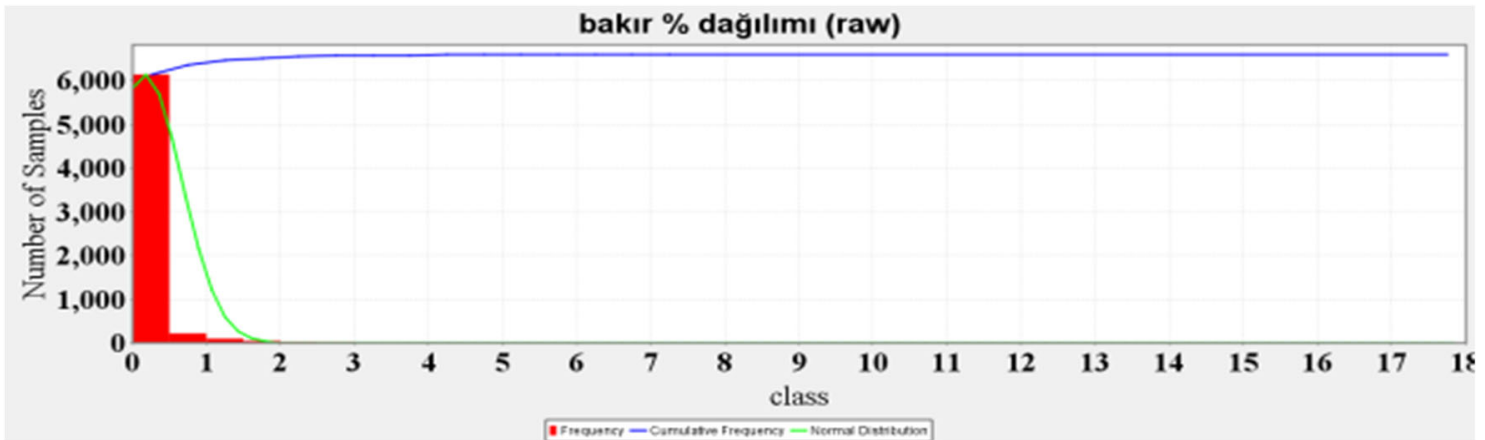

Şekil 3. Sondajlara göre $\mathrm{Cu} \%$ dağılım histogramı

Çalıșma alanında yapılan 25 adet sondajdan 6607 veritabanı dosyaları oluşturulmuştur. Bu verilerin bakır \% içerikleri $\% 0$ ile $\% 17,8506$ arasında değişmektedir. Veri açıklığı \%17,8506, ortalama bakır içeriği \%0,163192'dir. Standart sapma 0,50, varyans $0,25^{\prime}$ tir (Çizelge 1 ). Sondaj verilerine göre bakır \% dağılımına ait histogram Şekil 3'te verilmektedir. 
Çizelge 1. Sondajlara göre bakır \% dağılımı

\begin{tabular}{|l|r|}
\hline Örnek Say1s1 & 6607 \\
\hline En Küçük Değer & 0,000000 \\
\hline En Büyük Değer & 17,850600 \\
\hline Ortalama & 0,163192 \\
\hline Ortanca & 0,033400 \\
\hline Varyans & 0,253123 \\
\hline Standart Sapma & 0,503114 \\
\hline Değişim Katsay1s1 & 3,082956 \\
\hline Çarp1klık & 11,534776 \\
\hline Basıklık & 274,037438 \\
\hline & \\
\hline$\% 10,0$ & 0,008700 \\
\hline$\% 20,0$ & 0,013400 \\
\hline$\% 30,0$ & 0,019100 \\
\hline$\% 40,0$ & 0,025300 \\
\hline$\% 50,0($ Ortanca) & 0,033400 \\
\hline$\% 60,0$ & 0,045300 \\
\hline$\% 70,0$ & 0,071100 \\
\hline$\% 80,0$ & 0,139550 \\
\hline$\% 90,0$ & 0,344700 \\
\hline$\% 95,0$ & 0,720501 \\
\hline$\% 97,5$ & 1,333500 \\
\hline
\end{tabular}

\section{METOD}

İşletmede yapılan 25 adet sondaja ait bilgiler yardımıyla veri tabanı dosyaları oluşturulmuştur. Sondajlardaki cevherli zonlar kesitler alınarak birleştirilmiş ve kesitler arası DTM modülü ile doldurularak cevherin katı modeli elde edilmiştir (Şekil 4).
Sondaj verileri $1 \mathrm{~m}$ aralıklarla kompozit edilerek ağırlıklandırılmıştır. Maden yatağı blok model modülü yardımıyla $10 \mathrm{~m}$ x $10 \mathrm{~m}$ x $5 \mathrm{~m}$ boyutlu bloklara ayrılmıştır. Oluşturulan blok modele ait görünüm Şekil 5'te verilmiştir.

Oluşturulan bloklara maden yatağını temsil edecek bakır tenör değerlerinin atanması işlemi için jeoistatistik yöntem kullanılmıştır. Jeoistatistik yöntemde gözlemlerin yapıldı $\breve{1}$ noktaların konumları ve gözlemler arası korelasyon dikkate alınarak yansız ve minimum varyanslı kestirimler yapılabilmektedir [13].

Jeoistatistikte bölgesel değişkenin değerleri arasındaki farkın uzaklığa bağlı değişimleri variogram fonksiyonu ile ortaya konur. Belirlenen teorik variogram ve parametrelerin geçerliliğinin test edilmesi için Kriging ile çapraz doğrulamaya tabi tutulur. Kriging hem ölçülen değerlerden ve değerlerin konumsal ilişkilerinden enterpolasyon yapma hem de varyansı aracılığı ile kestirim hatasının büyüklüğünü değerlendirme imkânı sağlamaktadır. Çalışmada küresel (spherical) variogram modeli ile değişkenlerin ve ortalamanın sabit olduğu varsayımına dayanan ordinary kriging yöntemi kullanılmıştır. Nugget değeri 0,4426776, sill değeri 0,8150455 ve range değeri 95,294 olarak elde edilmiştir (Şekil 6).

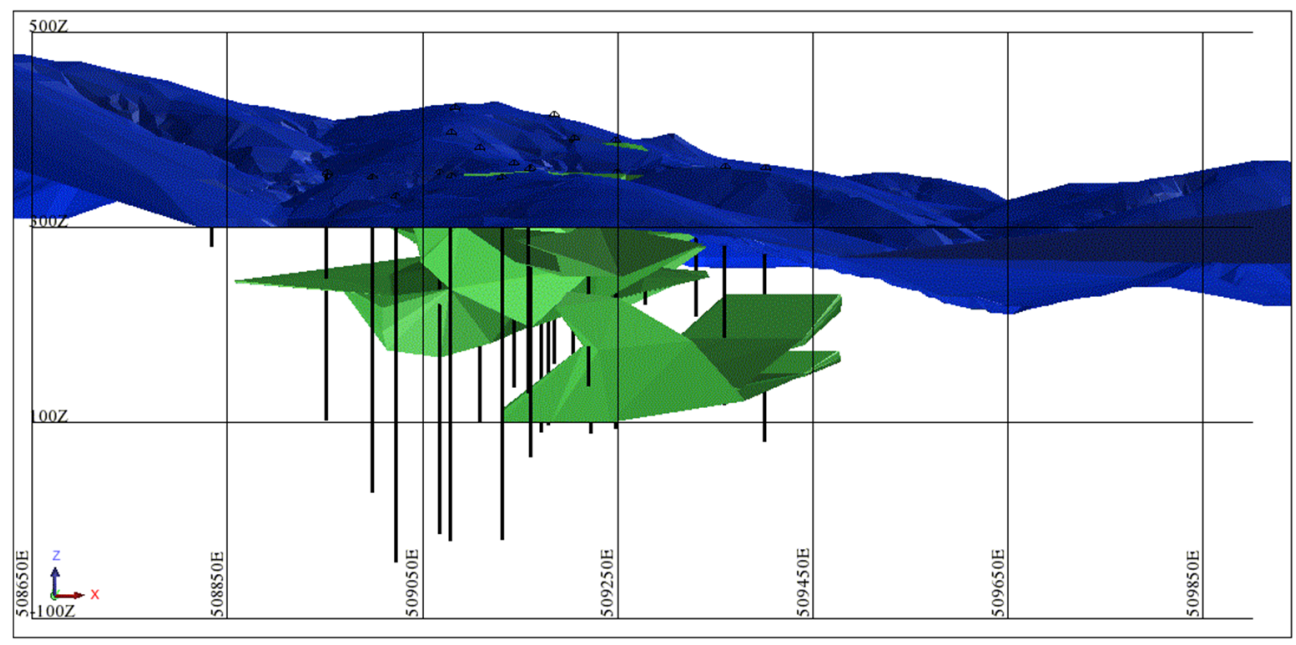

Şekil 4. Cevher katı modeli 


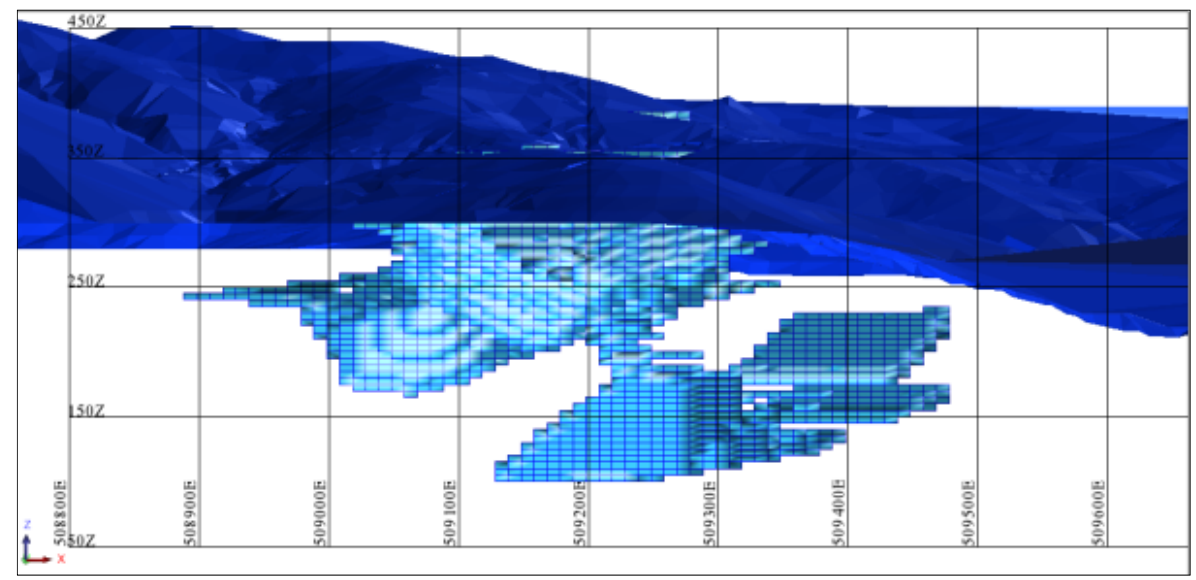

Şekil 5. Cevher blok modeli

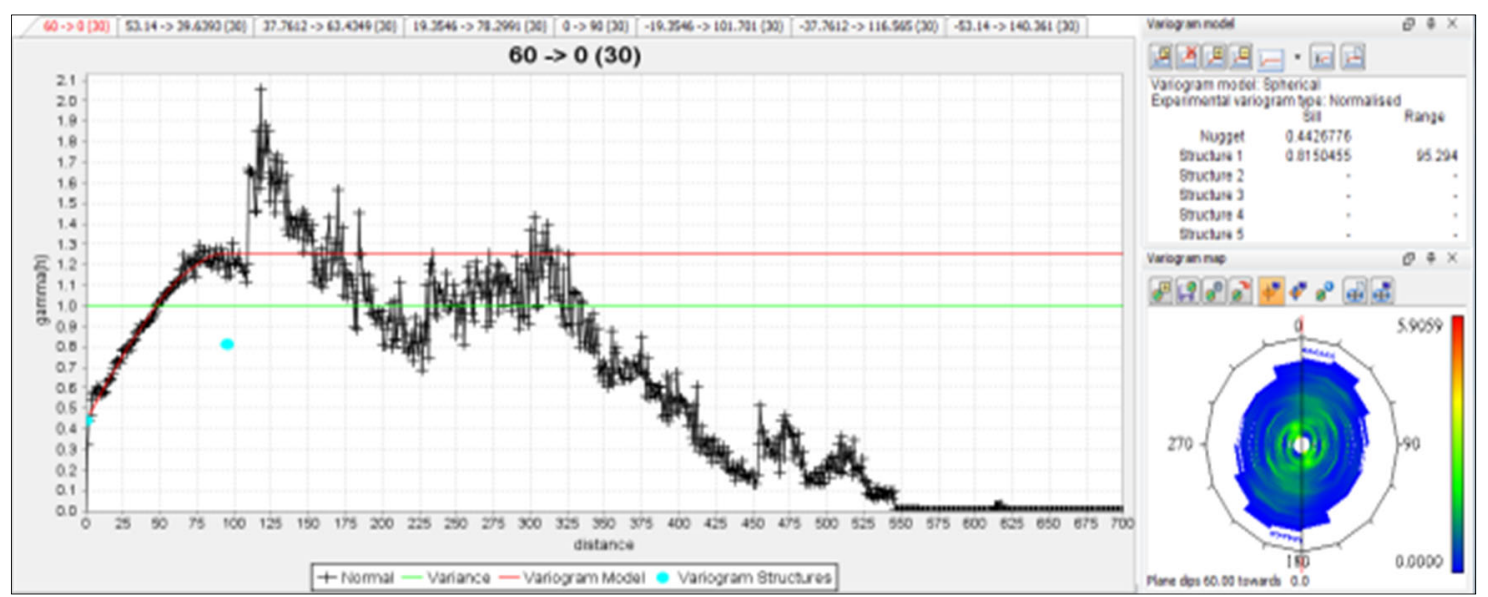

Şekil 6. Cu tenör variogramı ve parametreleri

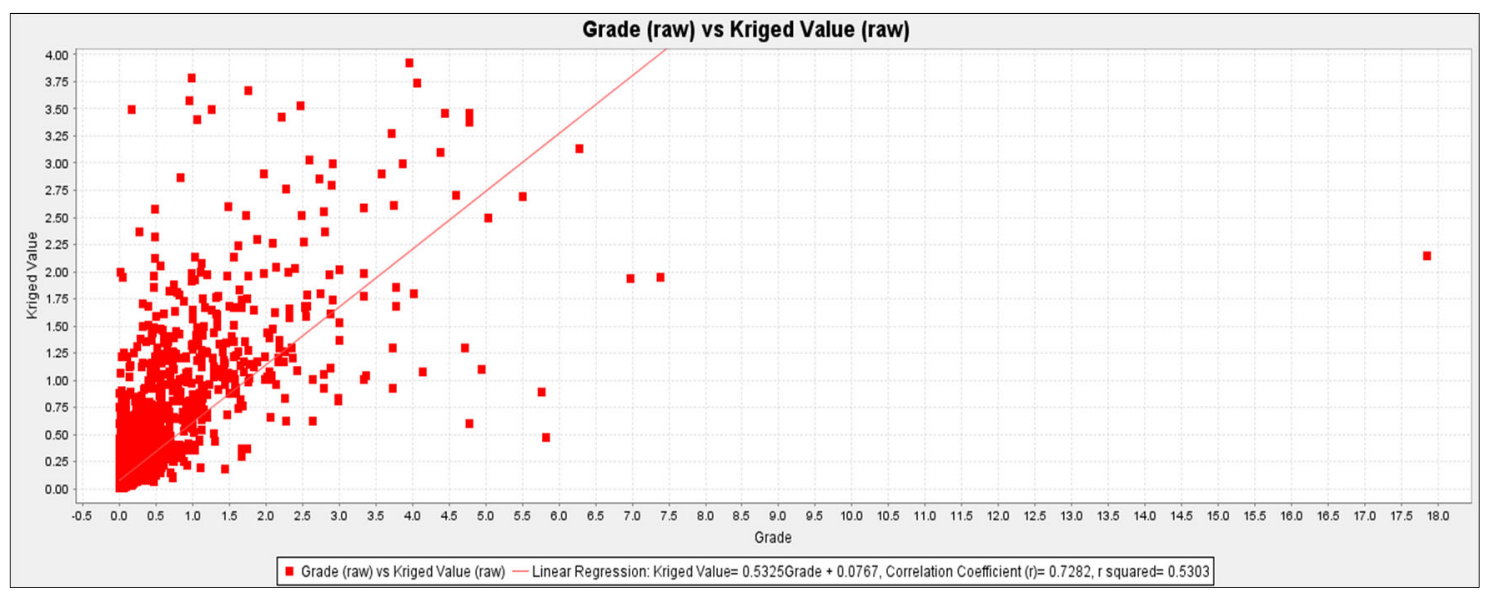

Şekil 7. Cu tenörü için belirlenen teorik variogram ve parametleri için çapraz doğrulama sonucu 
Çapraz doğrulamada gerçek değeri bilinen bir veri gerçek değeri bilinmiyormuş gibi, bilinen diğer veriler aracılığıyla noktasal kriging kestirim tekniği ile tahmin edilir. Bu işlem sonucunda elde edilen korelasyon katsayısının 1'e yakınlığ tahminlerdeki doğruluğu göstermektedir.
Şekil 7'de bakır tenörü için yapılan çapraz doğrulama sonucunda korelasyon katsayısının (r) 0,7282 olarak elde edildiği görülmektedir. $\mathrm{Bu}$ aşamanın ardından jeoistatistik yöntem ile elde edilen nugget, sill ve range değerleri kullanılarak bloklara bakır tenör değerleri atanmıştır (Şekil 8).

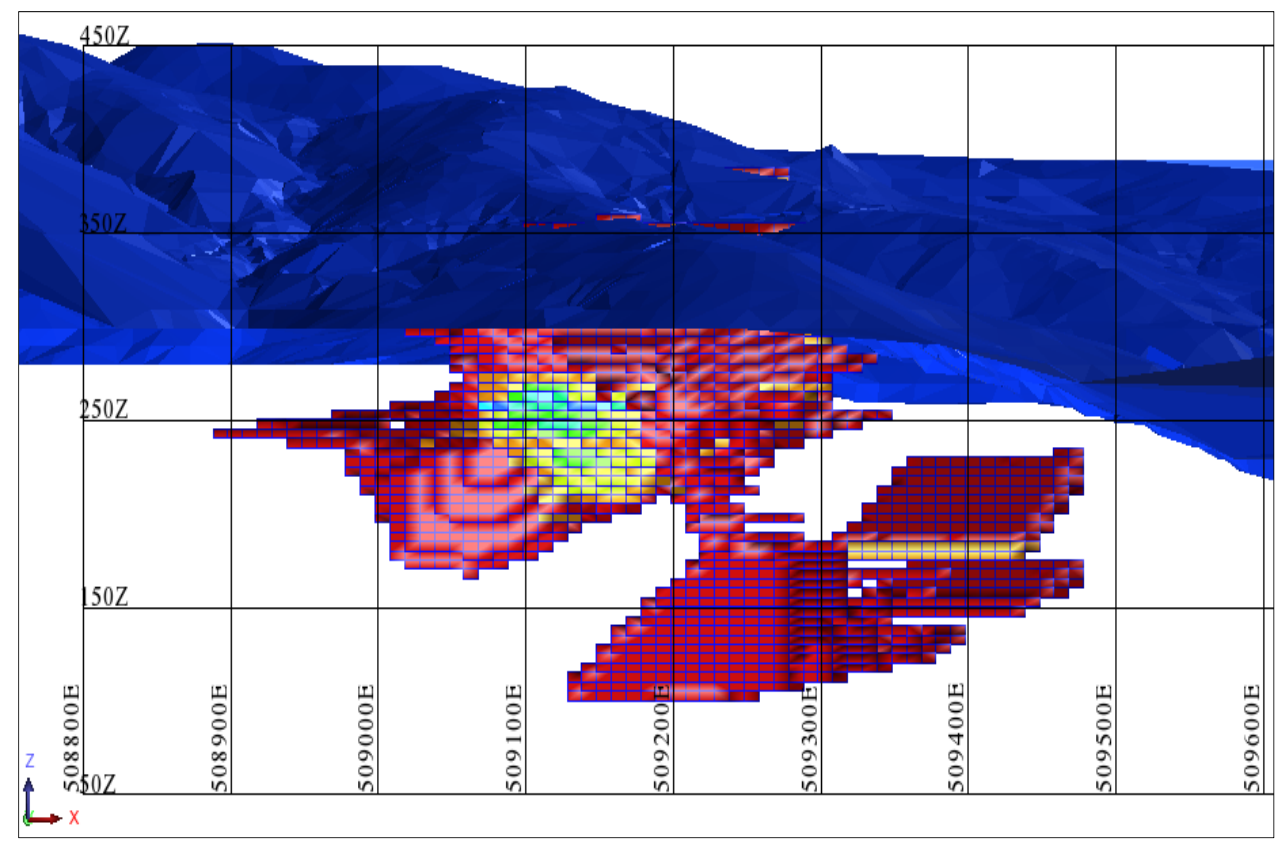

Şekil 8. \%Cu tenörüne göre renklendirilmiş blok model

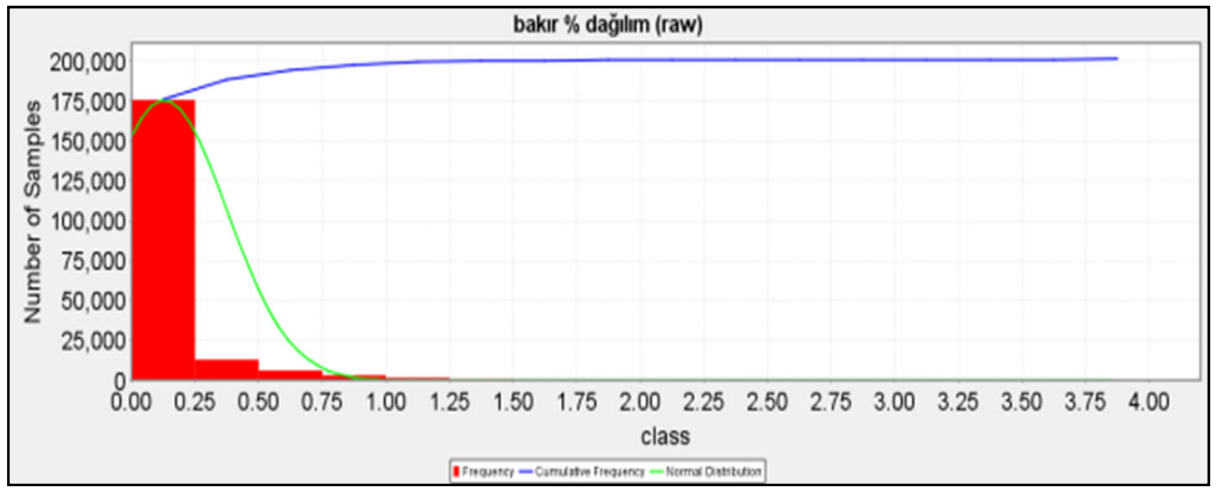

Şekil 9. Blok modele göre bakır \% dağılım histogramı

Sondajlara ait verilerden elde edilen bakır dağılımı verileri Çizelge 1'de yer almaktadır. Değer atama işleminden sonra blok modelden elde edilen bakır $\%$ dağılımı ise Çizelge 2'de verilmiştir. Blok modelden elde edilen 200.970 veri içerisinde en yüksek bakır içeriği \%3,854289, ortalama bakır içeriği \%0,129685'tir. Standart sapma 0,246747, varyans 0,060884 olarak hesaplanmıştır. Blok modele göre bakır \% dağılımını gösteren histogram Şekil 9'da verilmektedir. 
Çizelge 2. Blok modele göre bakır \% dağ 1 lımı

\begin{tabular}{|l|r|}
\hline Örnek Sayıs & 200970 \\
\hline En Küçük Değer & 0,000000 \\
\hline En Büyük Değer & 3,854289 \\
\hline Ortalama & 0,129685 \\
\hline Ortanca & 0,046243 \\
\hline Varyans & 0,060884 \\
\hline Standart Sapma & 0,246747 \\
\hline Değişim Katsay1S1 & 1,902656 \\
\hline Çarpıklı & 4,697161 \\
\hline Basılklı & 34,306946 \\
\hline & \\
\hline$\% 10,0$ & 0,006981 \\
\hline$\% 20,0$ & 0,019306 \\
\hline$\% 30,0$ & 0,027098 \\
\hline$\% 40,0$ & 0,035912 \\
\hline$\% 50,0$ (Ortanca) & 0,046243 \\
\hline$\% 60,0$ & 0,062919 \\
\hline$\% 70,0$ & 0,094279 \\
\hline$\% 80,0$ & 0,152637 \\
\hline$\% 90,0$ & 0,315415 \\
\hline$\% 95,0$ & 0,587552 \\
\hline$\% 97,5$ & 0,845205 \\
\hline
\end{tabular}

\section{AÇIK OCAK ÜRETIM PLANININ BELİRLENMESİ}

Çalışma alanında 17.359.902 tonluk bakır rezervi bulunmaktadır (cevher birim hacim ağırlığ 2,5 ton $/ \mathrm{m}^{3}$ kabul edilmiştir). Jeolojik yapı dikkate alınarak gerçekleştirilen cevher katı modeli içerisinde oluşturulan blok modelden elde edilen bu rezervin $\% \mathrm{Cu}$ ortalaması $\% 0,1290$ olarak hesaplanmıştır (Çizelge 2). Üretim planının belirlenebilmesi için oluşturulan iç içe ocaklar kavramına göre cevherin ton başına fiyatına farklı değerler verilerek elde edilen nihai açık ocak sınırları, işletmenin yıllık ilerleme yönünü de belirleyecektir. Bu örnek çalışmada kazı maliyeti cevher için 10,0 TL/ton, dekapaj için $8,0 \mathrm{TL} / \mathrm{m}^{3}$ olarak öngörülmüştür. Kabarma faktörü 1,35, kazı verimi $\% 95$, şev açıs $145^{\circ}$, satış maliyeti $6,0 \mathrm{TL} /$ ton, proses maliyeti 3,2 TL/ton, rehabilitasyon maliyeti 2,0 TL/ton olarak kabul edilmiştir. Kabul edilen bu değerlere göre, üretime başlanabilmesi için bakır fiyatının en az $1.000 \mathrm{TL} /$ ton olması gerekmektedir. Rezervin tamamının kazanılabilmesi için ise bakır fiyatının 26.338 TL/ton'a ulaşması gerekmektedir. Farklı bakır fiyatlarına karşılık nihai açık ocak sinırlarında meydana gelen değişimler hem Çizelge 3'te, hem de Şekil 10, Şekil 11 ve Şekil 12'de verilmektedir. Bu şekillere göre, ocak ilerleme yönü güneyden başlayıp kuzeye doğru olacak ve bu yönde ocak derinliği de artacaktır. Ocak sınırı batıya doğru genişledikçe ocak derinliği de artış gösterecektir.

Farklı ton başına cevher fiyatları ile iç içe ocaklar oluşturularak yapılacak dekapaj ve cevher kazı miktarları belirlenmiştir (Çizelge 3). Sahada üretim yapılabilmesi için Bakır fiyatının en az $1.000 \mathrm{TL} /$ ton olması gerekmektedir. Bakır birim fiyatları tarafımızca arttırıldıkça kazı miktarı artmakta ve ortalama tenör düşmektedir. Bakır fiyatının 26.338 TL'ye ulaşması durumunda 17.359.902 tonluk bakır rezervinin tamamının kazanılması mümkün olacaktır. Farklı cevher fiyatları için optimum açık ocak sınırı belirlenmesi aşamasında, Lerchs-Grossman tarafindan geliştirilmiş algoritma kullanılmıştır [14].

Çizelge 3. Cevher fiyatına bağlı olarak üretim parametrelerinde meydana gelen değişimler

\begin{tabular}{|c|c|r|r|r|r|r|}
\hline No & $\begin{array}{c}\text { Cevher Satış } \\
\text { Fiyat1 } \\
\text { (TL/ton) }\end{array}$ & $\begin{array}{c}\text { Cevher } \\
\text { Miktar1 } \\
\text { (ton) }\end{array}$ & $\begin{array}{c}\text { Dekapaj } \\
\text { Miktar1 } \\
\left(\mathrm{m}^{3}\right)\end{array}$ & $\begin{array}{c}\text { Örtü-Kazı } \\
\text { Oran1 } \\
\left(\mathrm{m}^{3} / \text { ton }\right)\end{array}$ & $\begin{array}{c}\text { Elde Edilecek Kar } \\
(\mathrm{TL})\end{array}$ & $\begin{array}{c}\text { Ocak ort. } \\
\text { Tenörü } \\
(\%)\end{array}$ \\
\hline 1 & 1.000 & 22.470 & 1.213 & 0,05 & 12.181 & 0,65 \\
\hline 2 & 1.690 & 827.837 & 204.965 & 0,25 & 2.833 .873 & 0,29 \\
\hline 3 & 1.700 & 3.897 .061 & 2.662 .140 & 0,68 & 1.227 .488 & 0,29 \\
\hline 4 & 3.000 & 7.976 .453 & 4.005 .654 & 0,50 & 63.967 .066 & 0,14 \\
\hline 5 & 3.300 & 9.010 .203 & 4.619 .678 & 0,51 & 82.084 .173 & 0,12 \\
\hline 6 & 4.000 & 11.593 .953 & 6.291 .839 & 0,54 & 131.049 .857 & 0,09 \\
\hline 7 & 6.000 & 14.378 .652 & 7.836 .535 & 0,55 & 289.693 .709 & 0,05 \\
\hline 8 & 7.000 & 15.573 .652 & 10.038 .659 & 0,64 & 374.824 .764 & 0,03 \\
\hline 9 & 26.338 & 17.359 .902 & 14.058 .774 & 0,81 & 2.147 .474 .792 & 0,02 \\
\hline
\end{tabular}




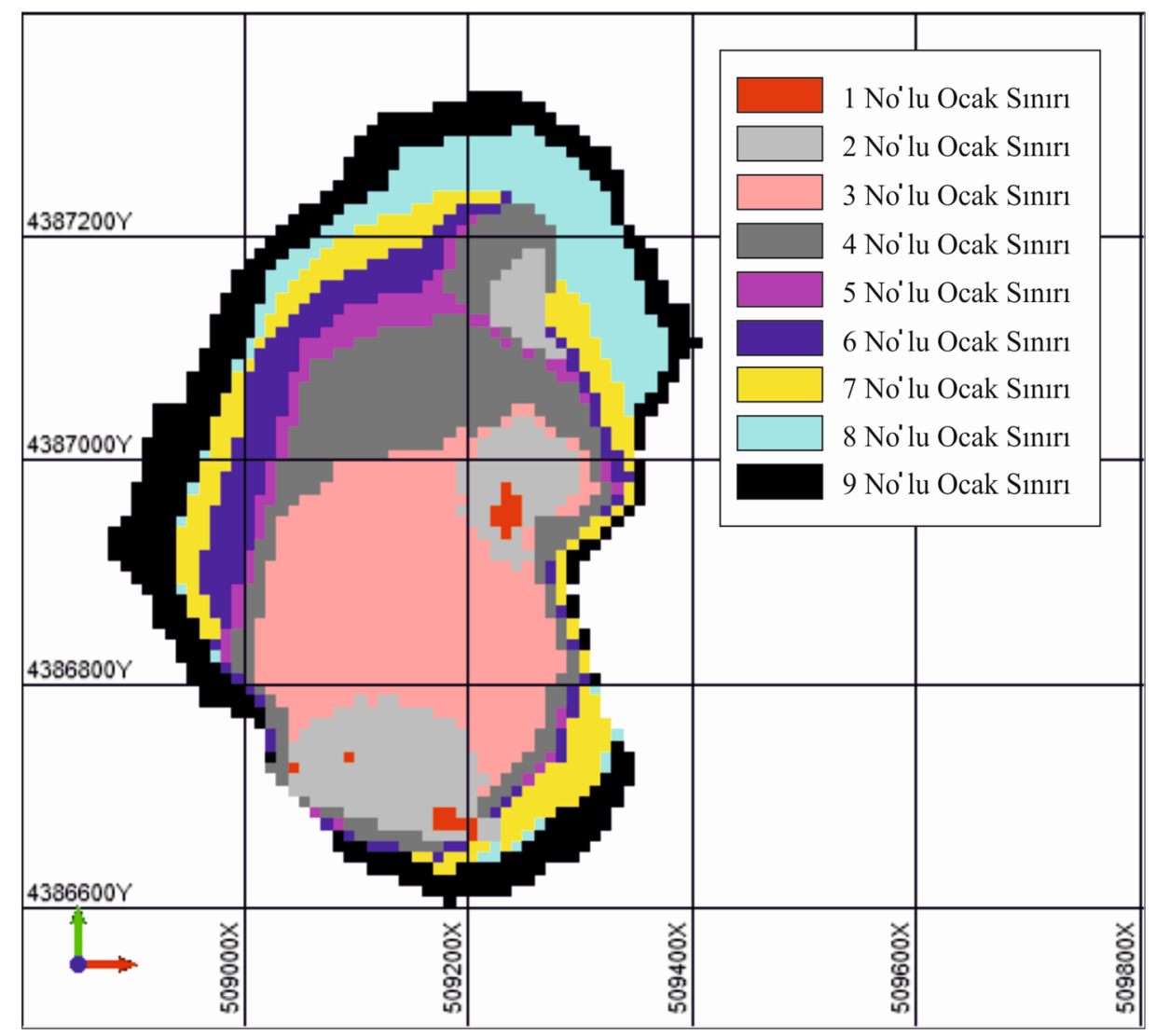

Şekil 10. Oluşan ocakların üstten görünümü

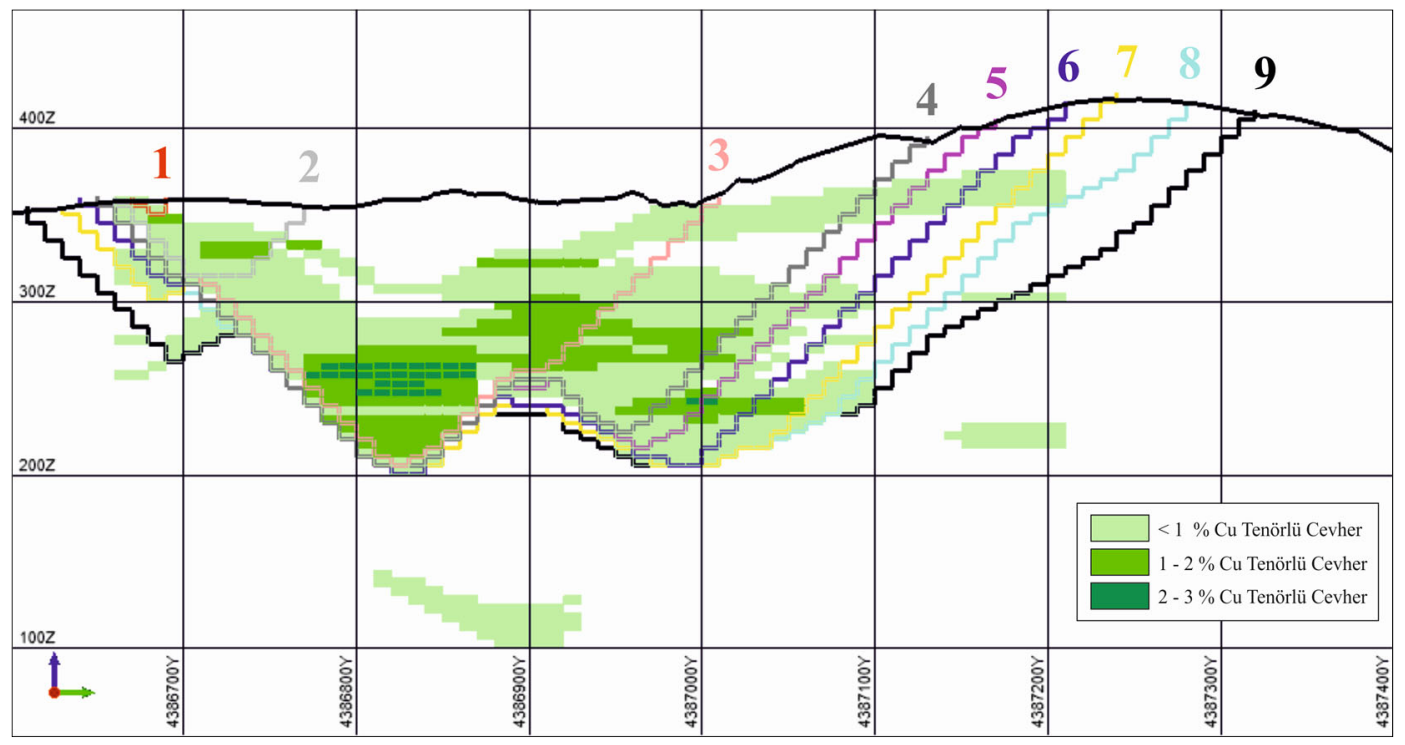

Şekil 11. Oluşan ocak sınırlarının kuzey-güney yönlü kesit görünüm 


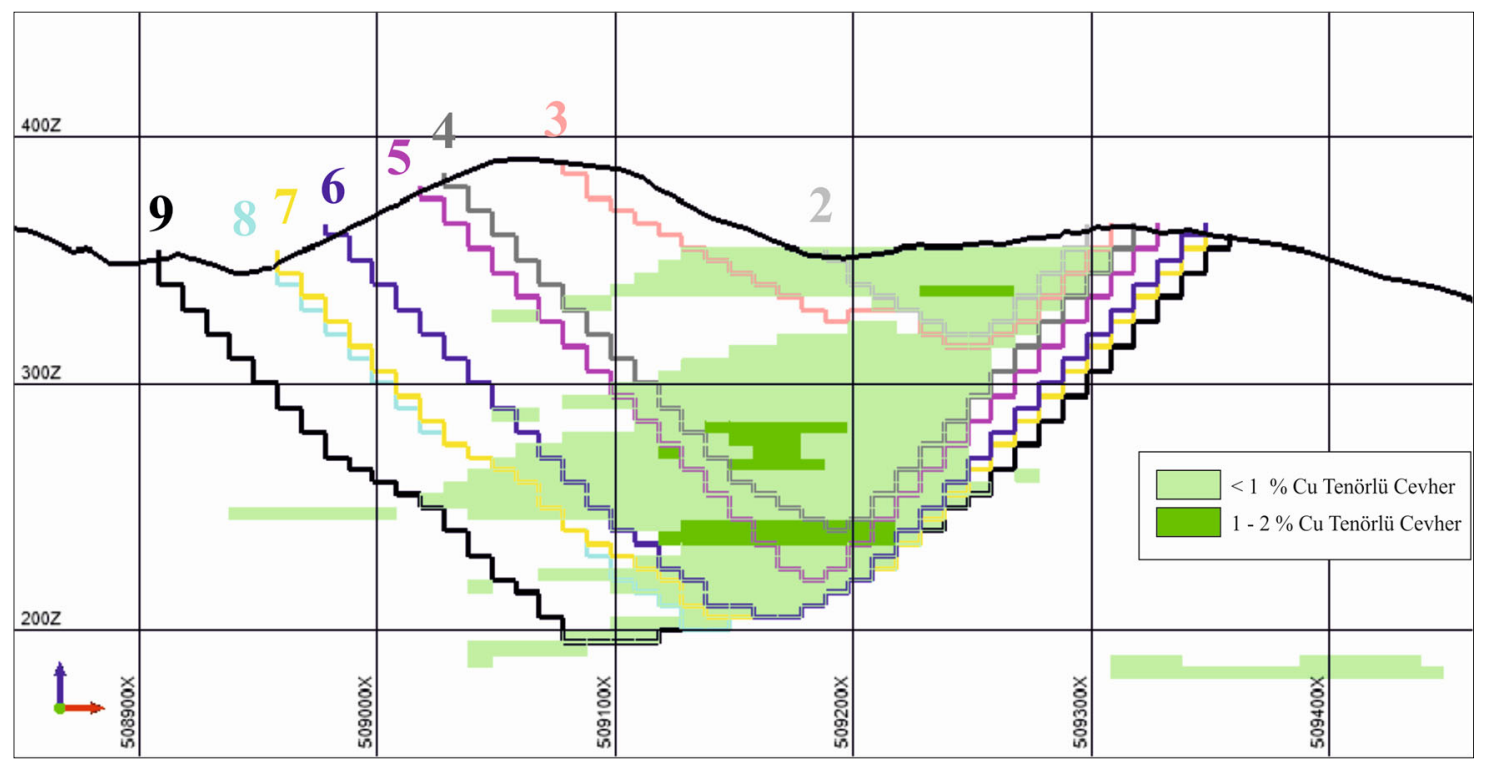

Şekil 12. Oluşan ocak sınırlarının doğu-batı yönlü kesit görünümü

Çizelge 3'de görüldüğü üzere, farklı cevher fiyatları için oluşturulan iç içe ocakların sınır tenör ve örtükazı oranları verilmektedir. Her bir ocak arasındaki değerler incelenerek, cevher hazırlama tesisine homojen cevher verilmesi ile ilgili değerlendirmeler gerçekleştirilmelidir. Ayrıca çizelgedeki örtü kazı oranları değerleri kullanılarak, makine ekipman parkının yıllık örtü kazı oranını karşılayabilecek yeterliliği araştırılmalıdır.

\section{SONUÇLAR}

Bu çalışmada, herhangi bir açık ocak tasarımı için planlama aşamasında gerçekleştirilecek tüm aşamalar bir örnek vasıtası ile verilmiş, sondaj verilerinin değerlendirilmesinden, açık ocak üretim planlamasına kadar tüm aşamalar gösterilmiştir. En yüksek net karı verecek açık ocak nihai sınırının belirlenmesi oldukça karmaşık bir işlemdir. Değişken fiyatlar ve paranın bugünkü değeri göz önüne alındığında, en son nihai üretim sınırını bugünkü üretim maliyetleri ve cevher satış fiyatları ile belirlemek doğru olmayacaktır. Doğru olmayan nihai sınır içerisinde yıllık üretim planı yapmakta doğru olmayacaktır. Açık ocak sınırı belirlenirken, pozitif kar yapabilecek en düşük cevher satış fiyatı ile bir ilk ocak oluşturulmaktadır. Bu durumdaki cevher fiyatı piyasadaki geçerli cevher fiyatından çok düşük olabilir. Amaç, çok düşük fiyatlarda dahi kar elde edilebilecek ilk açık ocak sınırını belirlemektir. Böyle bir durumda paranın bugünkü değeri ile indirgeme uygulamanın bir önemi kalmayacaktır. İlk pozitif karlı ocaktan daha karlı bir açık ocak olmayacağı için, cevher fiyatı artırılarak oluşturulan iç içe açık ocaklar, bir sonraki aşamada hangi yöne kazı gerçekleştirileceği ile ilgili planlamacıya önemli fikir verecektir.

$\mathrm{Bu}$ çalışmada cevher fiyatları $1.000 \mathrm{TL} /$ ton'dan 26.338 TL/ton'a farklı aralıklarda değiştirilerek iç içe açık ocaklar elde edilmiştir. Farklı açık ocak şev açıları, farklı kazı ve cevher hazırlama maliyeti değerleri ile optimum nihai sınır belirleme algoritması çalıştırılarak açık ocak ilerleme yönleri simüle edilebilir. Özellikle, ocak ilerlemeleri esnasında kullanılan iç içe ocakların cevher ve örtü miktarları, örtü kazı oranları ve cevher tenörleri, ekonomik değerlendirmeyle birlikte ele alınmalıdır.

\section{KAYNAKLAR}

1. Türk Mühendis ve Mimar Odaları Birliği, https://www.tmmob.org.tr, 15.06.2010 (Erişim tarihi 14.06.2019).

2. Demirbugan, A., 2015. Maden Projelerinin Değerlendirilmesinde Optimum Üretim 
Miktarlarının Belirlenmesi. Afyonkarahisar Üniversitesi Sosyal Bilimler Dergisi, 129-146.

3. Whittle, J., 1989. The Facts and Fallacies of Open Pit Optimization. Victoria: Whittle Programming Pty.

4. Özkan, M., 2015. Açık İşletmelerde Optimum Üretim Planlamasında Yeni Bir Yöntem Geliştirilmesi, Doktora Tezi, İstanbul Teknik Üniversitesi Fen Bilimleri Enstitüsü, İstanbul.

5. Onur, A. H., 1992. Optimal Open Pit Design and Planning, Doktora Tezi, University of Leeds, England.

6. Dağdelen, K., Johnson, T. B., 1986. Optimum Open Pit Mine Production Scheduling by Lagrangian Parameterization. 19 $19^{\text {th }}$ APCOM Symposium of the Society of Mining Engineers, 127-142.

7. Roman, R. J., 1974. The Role of Time Value of Money in Determining an Open Pit Mining Sequence and Pit Limits. Proceeding of $12^{\text {th }}$ APCOM Symposium, Colorado School of Mines, Golden Co.: 72-85.

8. Dowd, P., Onur, A., 1992. Optimising Open Pit Design and Sequencing. Proc. $23^{\text {rd }}$ International APCOM Symposium, 411-422.

9. Erarslan, K., Çelebi, N., 2001. A Simulative Model For Optimum Open Pit Design. Cim Bulletin, 59-68.

10. Matheron, G., 1975. Le Paramétrage des Contours Optimaux. Technique Notes (401), 19-54.

11. Ramazan, S., Dağdelen, K., Johnson, T., 2005. Fundamental Tree Algorithm in Optimising Production Scheduling for Open Pit Mine Design. Mining Technology, 45-54.

12. Avşar, M. K., 2006. Tepeoba (HavranBalıkesir) Cu-Mo-Au Sahasının Maden Jeolojisi Raporu. Balıkesir: MTA.

13. Yaprak, S., Arslan, E., 2008. Kriging Yönteminin Geoit Yüzeyi Modellemesinde Kullanılabilirlik Araştırması. İTÜ Dergisi Seri D: Mühendislik, 51-62.

14. Lerchs, H., Grossman, I. F., 1965. Optimum Design of Open-Pit Mines. CIM Bulletin, 47-54. 